\title{
LC and UV Methods for Lamotrigine Determination in Pharmaceutical Formulation
}

\author{
Magda T. Martins, Clésio S. Paim, and Martin Steppe \\ Faculdade de Farmácia, Universidade Federal do Rio Grande do Sul, Avendia Ipiranga, 2752/402, 90610-000 Porto Alegre, RS, Brazil
}

Correspondence should be addressed to Magda T. Martins, magdatm@terra.com.br

Received 12 July 2010; Revised 3 December 2010; Accepted 14 December 2010

Academic Editor: Toyohide Takeuchi

Copyright (๑) 2011 Magda T. Martins et al. This is an open access article distributed under the Creative Commons Attribution License, which permits unrestricted use, distribution, and reproduction in any medium, provided the original work is properly cited.

Liquid chromatography (LC) and ultraviolet spectrophotometric (UV) methods for lamotrigine (LTG) determination were validated. The LC separation was achieved on an ACE RP-18 as stationary phase and $0.3 \%$ triethylamine in water $(\mathrm{v} / \mathrm{v}) \mathrm{pH}$ $4.0:$ methanol $(62: 38, \mathrm{v} / \mathrm{v})$ as mobile phase. Detection was achieved with a photodiode array at $279 \mathrm{~nm}$. The detection response for LTG was linear $\left(r^{2}=0.9999\right)$. The specificity and stability were proved using stress conditions. The CV (\%) values for intraday and interday precision were less than $2.0 \%$. The method was accurate and robust. The $t$-student test proved that the LC and UV methods are interchangeable.

\section{Introduction}

The development of new antiepileptic drugs for epilepsy over the last decade has been spurred by the fact that the available antiepileptic drugs did not provide optimal care for patients with epilepsy [1]. LTG is a new antiepileptic drug that is currently used as an add-on therapy or monotherapy in patients with partial and secondary generalized seizures [2]. Lamotrigine (Figure 1), 3,5-diamino-6-(2,3dichorophenyl)-1,2,4-triazine, $\mathrm{C}_{9} \mathrm{H}_{7} \mathrm{Cl}_{2} \mathrm{~N}_{5}$, mol. Wt. $256 \mathrm{~g}$, is chemically unrelated with other antiepileptic drugs in current use, differing in structure and pharmacology. LTG has a broad spectrum in antiepileptic activity $[3,4]$. The efficacy of seizures treatment depends on the drug quality, which requires suitable monitoring. The quality controls of the anticonvulsant drugs are fundamental for the well-being of patients and are imperative for the development of routine analytical methods that can reliably measure these. Assays reported in the literature for lamotrigine determination in biological fluids include high-performance liquid chromatography [4-17]. Emami and collaborators [18] described a method for lamotrigine tablets by high-performance liquid chromatography, using reversed phase and related substances which may coexist in solid pharmaceutical dosage forms.
Youssef and Taha [19] described methods for lamotrigine determination in tablets using a liquid chromatography with reversed phase and colorimetric method at $529 \mathrm{~nm}$. A literature review revealed that an official monograph of LTG in tablets does not present in any pharmacopoeia. Recently, a validated stability-indicating LC method for lamotrigine using acetonitrile and aqueous trifluoroacetic acid was published [20]. Meanwhile, the aim of the present study was to develop and validate rapid, simple, and selective liquid chromatography method for LTG quality control in tablets. Furthermore, stress testing of the drug was also conducted, as required by the International Conference on Harmonization [21] to support the suitability of the method, corroborating the main advantage of this process in addition to the economic advantages of routine tests against the proposed methods found in the literature. The development of stability-indicating analytical method provides information about possible degradation pathways and demonstrates the capability of the analytical method in distinguishing LTG in presence of degraded products. The ICH guidelines requires performing stress testing of the drug substance, which can help identify the likely degradation products and can be useful to establish degradation pathways [21]. Due to this, the present method was validated by specificity, in placebo 
samples and forced-degradation samples, linearity, accuracy, repeatability, intermediate precision, and robustness.

\section{Experimental}

2.1. Materials. Lamotrigine reference substance (assigned purity of $99.41 \%$ ) was supported by Cristália Produtos Químicos Farmacêuticos LTDA (São Paulo, Brazil). The pharmaceutical dosage form (manufactured by Cristália Produtos Químicos Farmacêuticos LTDA, São Paulo, Brazil) as tablets for oral administration (claimed to contain $100 \mathrm{mg}$ of lamotrigine per tablet, and the following inactive ingredients: mannitol, pregelatinized starch, dibasic calcium phosphate, corn starch, sodium starch glycolate, magnesium stearate, crystallized silicon dioxide, and tartrazine yellow colorant) was obtained commercially.

LC-grade methanol was purchased from Tedia (Fairfield, USA). Triethylamine and phosphoric acid were purchased from Merck (Darmstadt, Germany). Distilled water purified by a Millipore Milli-Q UF-Plus apparatus (Millipore) was used to prepare the mobile phase. The $0.01 \mathrm{M} \mathrm{HCl}$ solutions were prepared using Quimex (Merck, Brazil) concentrated hydrochloric acid and purified water.

2.2. Instrumentation and Chromatographic System. The assay was developed and validated using an Agilent liquid chromatograph (Santa Clara, CA, United States) equipped with a model LC-1200 series with G1311A Quaternary pump, ALS G1329A auto sampler, TCC G1316A thermostat column compartment, DAD G1315B photodiode array detector, SCL-10Avp system controller and ChemStation manager system software which was used to control the equipment and calculate data from the LC system. Chromatographic separation was achieved in an ACE RP-18 octadecyl silane column $(150 \mathrm{~mm} \times 4.6 \mathrm{~mm}$ i.d., particle size $5 \mu \mathrm{m})$ maintained at room temperature. The mobile phase was composed of triethylamine $0.3 \%$ in water $(\mathrm{v} / \mathrm{v}) \mathrm{pH} 4.00$, adjusted with phosphoric acid $10 \%$ and methanol $(62: 38$, $\mathrm{v} / \mathrm{v})$. The flow rate was $1.0 \mathrm{mLmin}^{-1}$ with isocratic elution. The mobile phase was prepared daily, filtered through a $0.45 \mu \mathrm{m}$ membrane filter (Millipore) and degassed by the chromatographic system prior to use. LTG was determined by UV photodiode array at $279 \mathrm{~nm}$. The injection volume was $20 \mu \mathrm{L}$, and the time run was 10 minutes.

An UV-VIS recording spectrophotometer UV-160A (Shimadzu, Kyoto, Japan) at $267 \mathrm{~nm}$, using $1.0 \mathrm{~cm}$ quartz cells and S M software was used for the development and validation of UV method.

The Digimed potentiometer, model DM-20 (São Paulo, Brazil), was used to determine the $\mathrm{pH}$ of solutions.

The ultrasonic bath UCS 5000 (Unique, São Paulo, Brazil) was used for solutions preparation.

\subsection{Samples Preparation}

2.3.1. Samples for LC Analysis. The LTG standard stock solutions were prepared by dissolving pure, accurately weighed compound in methanol, obtaining $500 \mu \mathrm{gmL}^{-1}$.

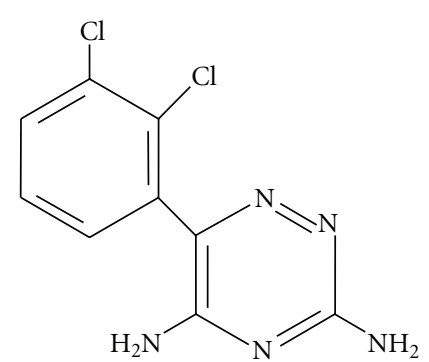

FIGURE 1: Chemical structure of lamotrigine.

This solution was kept in an ultrasonic bath for 15 minutes. Appropriate dilution of this stock solution was prepared using mobile phase to obtain $40 \mu \mathrm{gmL}^{-1}$, as the reference standard solution.

Twenty tablets were weighed, and the average weight was calculated. Tablets were crushed to a fine powder. An amount of the powdered tablets, equivalent to $25 \mathrm{mg}$ of lamotrigine, was transferred to $50 \mathrm{~mL}$ volumetric flask with methanol. This flask was kept in an ultrasonic bath for 15 minutes and then shaken for 15 minutes by a mechanical shaker. The volume was completed with methanol and the solution reached $500 \mu \mathrm{gmL}^{-1}$. The solution was filtered through a $0.45 \mu \mathrm{m}$ membrane filter (Millipore), and an aliquot of the filtrate $(4.0 \mathrm{~mL})$ was diluted with the mobile phase in a $50 \mathrm{~mL}$ volumetric flask to $40 \mu \mathrm{gmL}^{-1}$, as the working sample solution.

2.3.2. UV Method Samples. Lamotrigine reference standard was accurately weighed $(10.0 \mathrm{mg})$ and dissolved with $10 \mathrm{~mL}$ of $0.01 \mathrm{M} \mathrm{HCl}$ in a $20 \mathrm{~mL}$ volumetric flask. It was kept in an ultrasonic bath for 15 minutes. The volume was completed with the same solvent $\left(500 \mu \mathrm{gmL}^{-1}\right)$. An aliquot of $2.0 \mathrm{~mL}$ of this solution was diluted in a $50 \mathrm{~mL}$ volumetric flask, and the volume was completed with the same solvent $\left(20 \mu \mathrm{gmL}^{-1}\right)$.

Twenty tablets were accurately weighed and finely powdered. An amount equivalent to $25 \mathrm{mg}$ of lamotrigine was transferred to a $50 \mathrm{~mL}$ volumetric flask with $25 \mathrm{~mL}$ of $0.01 \mathrm{M}$ $\mathrm{HCl}$. This volumetric flask was kept in an ultrasonic bath for 15 minutes and shaken by a mechanical shaker for 15 minutes. The volume was completed with the same solvent $\left(500 \mu \mathrm{gmL}^{-1}\right)$, and the solution was filtered. An aliquot of $2.0 \mathrm{~mL}$ of this solution was diluted in a $50 \mathrm{~mL}$ volumetric flask, and the volume was completed with $0.01 \mathrm{M} \mathrm{HCl}$ $\left(20 \mu \mathrm{gmL}^{-1}\right)$.

\subsection{Validation of LC Method}

2.4.1. Specificity. At the first moment, the specificity was evaluated through the placebo sample solution. It was prepared in the same way of the sample solution in the presence of all inactive ingredients of the formulation but without lamotrigine. Forced degradation studies were performed in order to provide an indication of stability and method specificity [21-23]. The main focus has been generating representative degradation samples for developing 
stability-indicating analytical method. Stress testing should include the effect of temperature, oxidation, photostability, and susceptibility of the drug substance to hydrolysis across a wide $\mathrm{pH}$ range when in solution [22]. Samples submitted to forced degradation should be controlled to avoid the appearance of secondary degradation products. It is interesting to degrade around $5-15 \%[22,23]$. The stress conditions employed were UV C light, oxidant media, acid, base, temperature, acid associated with heat, and base associated with heat. Samples were analyzed against freshly prepared solutions. The solutions were analyzed through their chromatographic profiles and the peak purity tool was used. The placebo solutions were submitted to the same degradation conditions to verify any interference. All solutions were injected in triplicate.

2.4.2. Effect of UV Light. An amount of powder equivalent to $20 \mathrm{mg}$ of lamotrigine from crashed tablets was transferred to a $20 \mathrm{~mL}$ volumetric flask with methanol $\left(1 \mathrm{mgmL}^{-1}\right)$; the solution was submitted to an ultrasonic bath for 15 minutes. An aliquot of $1 \mathrm{~mL}$ from this solution was placed in a stopped-flow spectrophotometer $1 \mathrm{~cm}$ cell (Plastibrand) and wrapped with parafilm. The lamotrigine methanol solutions $(n=3)$ were exposed for $24 \mathrm{~h}$ to UV chamber $(100,18,17 \mathrm{~cm})$ with mirrors and an UV fluorescent lamp, model $30 \mathrm{~W}$ Ecollume $\mathrm{ZW}$ emitting radiation at $254 \mathrm{~nm}$. After the degradation treatment, the samples were diluted to $40 \mu \mathrm{gmL}^{-1}$ with mobile phase. Samples submitted to identical conditions, but protected from light by aluminum foil, were used as control.

2.4.3. Effect of Alkaline Hydrolysis. In order to carry out the alkaline hydrolysis and acid hydrolysis, a stock solution of lamotrigine was prepared in methanol $\left(2.0 \mathrm{mgmL}^{-1}\right)$. An aliquot of $5.0 \mathrm{~mL}$ was diluted in a $10 \mathrm{~mL}$ volumetric flasks with $1.0 \mathrm{M} \mathrm{NaOH}$ and $1.0 \mathrm{M} \mathrm{HCl}$. The solutions were allowed to react for $2 \mathrm{~h}$ and $7 \mathrm{~h}$ at room temperature. After that, $2.0 \mathrm{~mL}$ of the solutions were transferred to a $50 \mathrm{~mL}$ volumetric flask, neutralized with $1.0 \mathrm{M} \mathrm{HCl}$ (alkaline solution) and $1.0 \mathrm{M} \mathrm{NaOH}$ (acid solution) and then diluted with mobile phase to $40 \mu \mathrm{gmL}^{-1}(n=3)$, filtered, and analyzed by LC method.

The effects of both parameters (hydrolysis and heat) were also evaluated, since no degradation peaks could be observed under acid or base conditions. $2.0 \mathrm{~mL}$ were kept from the acid and alkaline stock solutions and allowed to react for $2 \mathrm{~h}$. The flasks containing the solutions were kept in a bath with controlled temperature $\left(80^{\circ} \mathrm{C}\right)$ for $2 \mathrm{~h}$. After that, the solutions were neutralized with $1.0 \mathrm{M} \mathrm{NaOH}$ (acid solution) and $1.0 \mathrm{M} \mathrm{HCl}$ (alkaline solution), diluted with mobile phase to $40 \mu \mathrm{gmL}^{-1}(n=3)$, filtered, and analyzed by LC method.

2.4.4. Effect of Oxidation. To promote the oxidation, a stock solution was prepared in methanol $\left(2.0 \mathrm{mgmL}^{-1}\right)$. An aliquot of $5.0 \mathrm{~mL}$ was diluted in a $10 \mathrm{~mL}$ volumetric flask with $30 \%$ hydrogen peroxide solution and left to react for $6 \mathrm{~h}$ at room temperature. After that, the solution was diluted in mobile phase to $40 \mu \mathrm{gmL}^{-1}(n=3)$, filtered, and analyzed by LC method.

2.4.5. Effect of Heat. An amount of powder equivalent to a $50 \mathrm{mg}$ of lamotrigine was transferred to a $50 \mathrm{~mL}$ volumetric flask with $\mathrm{HCl} 0.01 \mathrm{M}$. An aliquot of $1.0 \mathrm{~mL}$ from this stock solution was placed in a glass flask and kept in an oven for six days to study the effect of heat $\left(60^{\circ} \mathrm{C} \pm 1\right)$. After the specified time, this solution was diluted to $40 \mu \mathrm{gmL}^{-1}$ with mobile phase.

\subsection{Linearity and Limits of Detection (LOD) and Quantitation} (LOQ). The linearity of the method was tested on standard curves ranging from 10.0 to $80.0 \mu \mathrm{gmL}^{-1}$. Appropriate amounts of lamotrigine stock solution $\left(0.5 \mathrm{mgmL}^{-1}\right)$ were diluted with mobile phase and prepared in triplicate. The linearity was evaluated by linear regression analysis, which was calculated by the least-square regression analysis.

The LOD (detection limit) and LOQ (quantitation limit) were evaluated using a sequence of dilutions with known concentrations. The minimum concentration at which the lamotrigine can be detected (LOD) and quantified (LOQ) was established by the ChemStation software with the measure of $\mathrm{S}: \mathrm{N}$ (signal : noise) in the HPLC equipment [24].

2.5.1. Precision. Precision of the method was determined by repeatability (intraday precision) and intermediate precision (interday precision), analyzing six lamotrigine sample solutions prepared at $40.0 \mu \mathrm{gmL}^{-1}$ in triplicate in three different days $[25,26]$. The results were expressed as coefficient of variation $(\mathrm{CV} \%)$ of the measurements.

2.5.2. Accuracy. This parameter was determined by the recovery test, which consisted of adding known amounts of lamotrigine reference standard to the samples' solutions in the beginning of the process. This test was realized by assaying three different solutions, three replicates each, containing $10.0,20.0$, and $40.0 \mu \mathrm{gmL}^{-1}$ of lamotrigine standard solution added to lamotrigine sample solution, corresponding to 25 , 50 , and $100 \%$ of the nominal analytical concentration of lamotrigine $\left(40 \mu \mathrm{gmL}^{-1}\right)$.

2.5.3. Robustness. Robustness was evaluated by small changes made in the chromatographic conditions, such as $\mathrm{pH}$ values of aqueous phase, percentage of methanol in the mobile phase, and flow rate. For each experimental run, two injections were performed: lamotrigine sample and lamotrigine standard solution, both with the same concentration $\left(40 \mu \mathrm{gmL}^{-1}\right)$.

2.5.4. System Suitability. System suitability tests are based on the concept that the equipment, electronics, analytical operations, and samples to be analyzed constitute an integral system that can be evaluated as such. This parameter ascertains the suitability and effectiveness of the operating system $[26,27]$. The parameters available were theoretical plates, capacity factor, peak asymmetry, or tailing factor. 
2.5.5. Solutions Stability. Lamotrigine stock standard solutions were prepared in methanol and $0.01 \mathrm{M} \mathrm{HCl}$ $\left(500 \mu \mathrm{gmL}^{-1}\right)$, stored at $4^{\circ} \mathrm{C}$, and analyzed in the period of a month by LC method to verify this stability in both solvents.

\subsection{Validation of UV Method}

2.6.1. Specificity. The method specificity evaluation was performed by preparing a placebo containing the same excipients of the commercial product.

2.6.2. Linearity. The linearity was analyzed through the standard curves ranging from 5.0 to $40.0 \mu \mathrm{gmL}^{-1}$. A stock solution $\left(500 \mu \mathrm{gmL}^{-1}\right)$ of lamotrigine was prepared, used for dilution and preparation of three calibration curves in the same day with the following concentrations (5.0, 10.0, 15.0, 20.0, 25.0, 30.0, and $40 \mu \mathrm{gml}^{-1}$ ). The linearity was evaluated by linear regression analysis, which was calculated by the least square regression method.

2.6.3. Precision. The precision was determined in six replicates of lamotrigine samples $\left(20.0 \mu \mathrm{gmL}^{-1}\right)$ by repeatability (intraday precision) and interday precision. The CV\% was determined.

2.6.4. Accuracy. Accuracy was performed by recovery of known amounts of lamotrigine reference standard added to the samples in the beginning of the process. This test was realized by assaying three different solutions, three replicates each, containing 5.0, 10.0, and $20.0 \mu \mathrm{gmL}^{-1}$, of lamotrigine standard solution added to lamotrigine sample solution, which corresponds to 25,50 , and $100 \%$ of the nominal analytical concentration of lamotrigine $\left(20 \mu \mathrm{gmL}^{-1}\right)$.

2.6.5. Robustness. The robustness was evaluated making changes in the step of drug extraction, using ultrasonic bath for 15 minutes, mechanical shaker for 15 minutes, or both. Three replicates of each one were used. The methods were compared and analyzed by analysis of variance (ANOVA).

2.6.6. Sensitivity. The LOD and LOQ were mathematically determined using directly the calibration plot. It as calculated as $3.3 \rho / S$ and $10 \rho / S$, respectively, where $\rho$ is the standard deviation of intercept and $S$ is the slope of the calibration plot [22].

\section{Results and Discussion}

\subsection{LC Method}

3.1.1. Selection of Chromatographic Conditions. The HPLC procedure was optimized to develop a method to determine lamotrigine when the drug was submitted to degradation conditions. The literature review revealed that, at this time, the HPLC has been considered as the technique of choice for the separation and determination of lamotrigine. The chromatographic conditions were chosen after words to test different mobile phases with different proportions of organic solvent. Methanol is commonly used as an organic solvent in HPLC, and reversed-phase chromatography was performed with various mixtures of methanol-water [23]. The $\mathrm{pH}$ value of aqueous phase was checked before mixing with methanol. The adjustment of solution to $\mathrm{pH}$ less than 4.5 results in lamotrigine predominantly as the ionized form $(\mathrm{pKa}=5.7)$ with $\lambda_{\max }$ at about $270 \mathrm{~nm}$. The acid value of $\mathrm{pH}$ is important to maintain the lamotrigine soluble in the mobile phase. Aqueous phases containing phosphate buffers were also described in the literature. Acceptable separations, with a retention time of 6.5 minutes for lamotrigine, were obtained using an Ace RP-18 octadecyl silane column $(150 \mathrm{~mm} \times 4.6 \mathrm{~mm}$, particle size $5 \mu \mathrm{m})$ and the mobile phase composed of $0.3 \%$ triethylamine in water $(\mathrm{v} / \mathrm{v}) \mathrm{pH} 4.0$ and methanol $(62: 38, \mathrm{v} / \mathrm{v})$. A simple mobile phase without buffer addition is an advantage in routine analysis, since it requires short time in equipment and column cleaning. The basic additive triethylamine was important to improve peak shapes that could be observed in Figure 2. The retention time observed allows a fast determination of the drug, which is important for routine analysis.

3.1.2. Specificity. An essential requirement for the separation analysis is to verify the purity of the separated species and the conviction that nothing is interfering with the principal peak [24]. The LC chromatograms recorded for the mixture of the inactive ingredients revealed no peaks within retention time around 6.5 minutes, and the peak purity was $99.99 \%$ (Figure 3).

Lamotrigine solutions were submitted to forced degradation studies to induce the presence of degraded products. The guidelines explicitly require conduct of forced decomposition studies under a variation of conditions, like $\mathrm{pH}$, light, oxidation, dry heat, and separation of drug from degradation products [24]. The assays with UV light are an integrate part of stress tests. In literature review, guanabenz, which is chemically similar to lamotrigine, is sensitive to acid, alkali and light stress conditions $[24,25]$. When submitted to UV radiation for $24 \mathrm{~h}$, the drug content exhibited a decrease (9\%), but there were no degradation peaks detectable in the chromatogram. Under alkaline conditions, lamotrigine content had a decrease for $2 \mathrm{~h}(12,6 \%)$ and more extensively for $7 \mathrm{~h}(23,7 \%)$, but there were no detectable degradation peaks. The samples submitted to acid conditions showed a similar degradation profile to that done in alkaline settings but less was extensive $(8,8 \%)$ for $2 \mathrm{~h}$ and $(14,9 \%)$ for $7 \mathrm{~h}$. When the exposition was an association of acid and heat or base and heat, the extent of degradation was higher and additional peaks emerged. The good resolution of lamotrigine peak and the other ones in both situations could be observed (Figure 4). Lamotrigine peak purity was 99.99\% for acid and alkaline conditions associated with heat. We could observe two degradation products more hydrophobic than lamotrigine that elutes with a longer retention time on a reversed-phase column. They appeared in 8 minutes (D8) and 10 minutes (D10). These degradation products are formed by promoting of heat being more extensively 


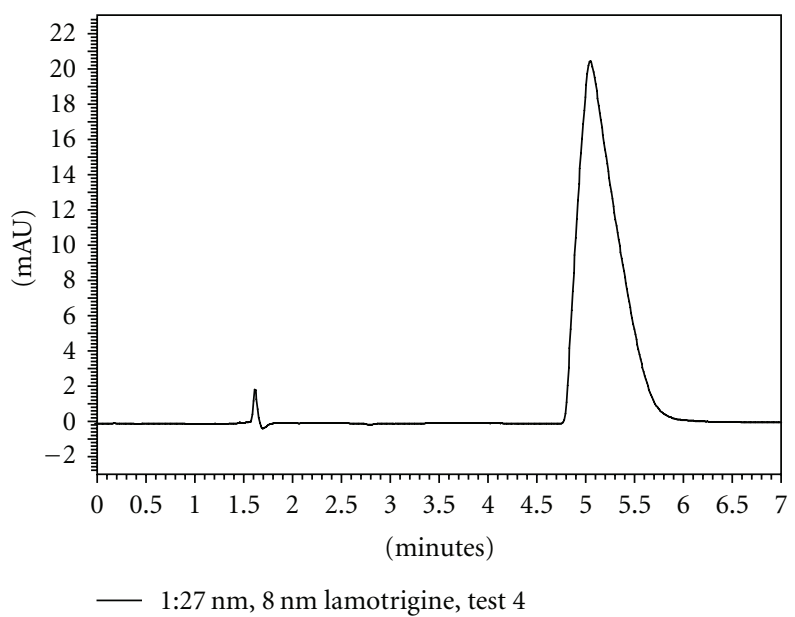

(a)

FIGURE 2: Mobile phase without the additive triethylamine $(0.3 \%)$ triethylamine $(0.3 \%)$ in the mobile phase (b).

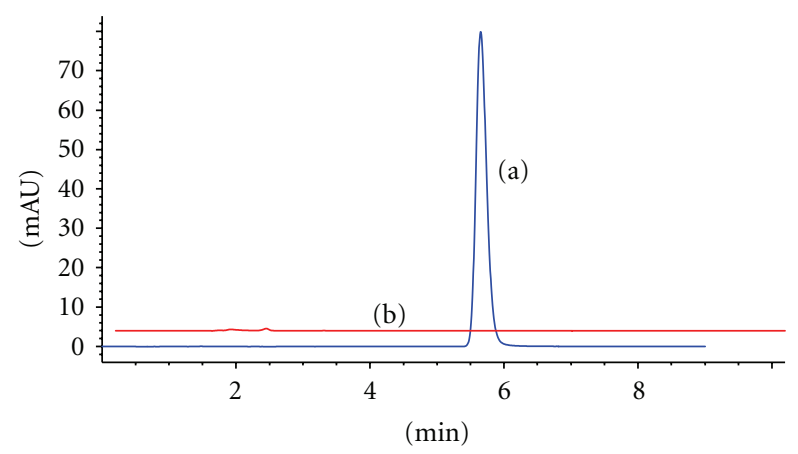

Figure 3: Representative chromatograms of lamotrigine (a) and drug-matrix solution (b).

in alkaline conditions. The peak purity of D8 was $99.97 \%$ and for D10 it was $99.99 \%$, suggesting interesting products to be isolated and studied. This method could separate these degradation products, becoming a stability-indicating method.

When the oxidation with $\mathrm{H}_{2} \mathrm{O}_{2} 30 \%$ was promoted, it did not show any emerged peaks in the chromatogram and the lamotrigine content had a little decrease $(5,3 \%)$. The same situation occurred with the temperature $\left(60^{\circ} \mathrm{C}\right)$ for 6 days that did not promote lamotrigine degradation $(2,3 \%)$, demonstrating that temperature is not a preponderant factor in lamotrigine degradation.

The chromatographic peak purity tool, applied for lamotrigine peak in the chromatogram, demonstrated that it was pure in all cases, confirming the absence of other substance in the same retention time. Since the main peak of lamotrigine was not found attributable to any other peak, the method proves to be suitable to analyze this drug. When the area decreased and degradation peaks were not observed in chromatogram, this could be attributed to the situation when the products formed do not absorb UV radiation [23]. The

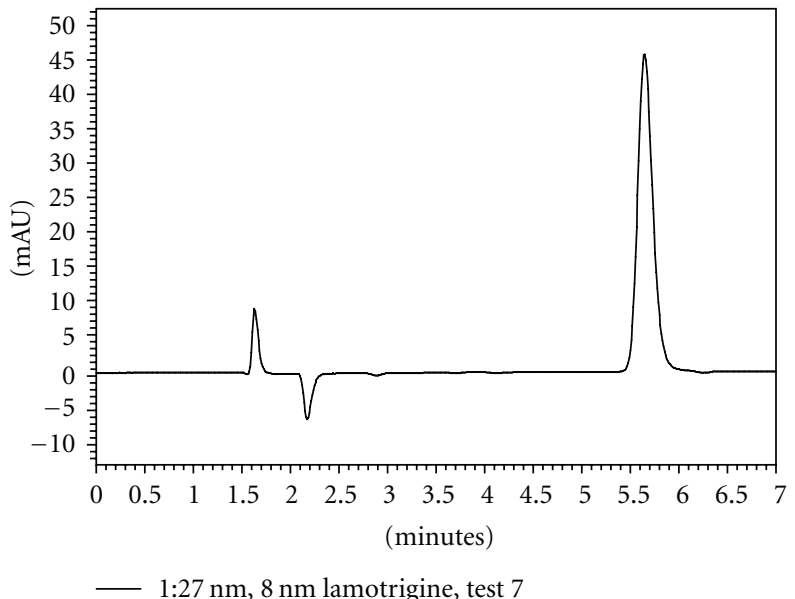

(b)

(a) and the use and influence in peak shapes with the additive (a) and the use and influence in peak shapes with the additive

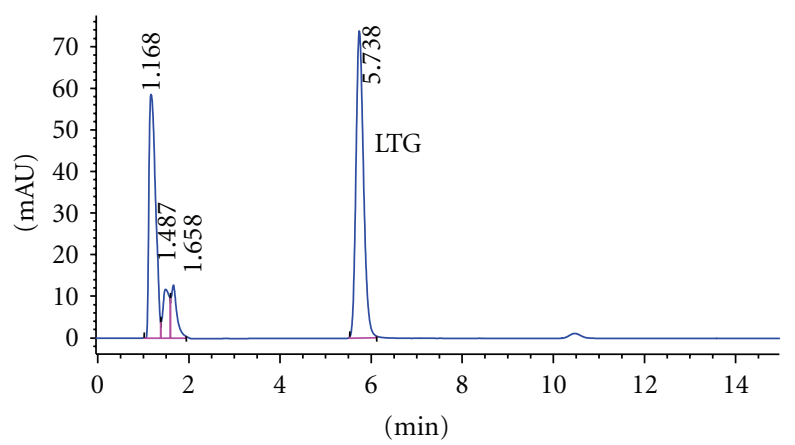

(a)

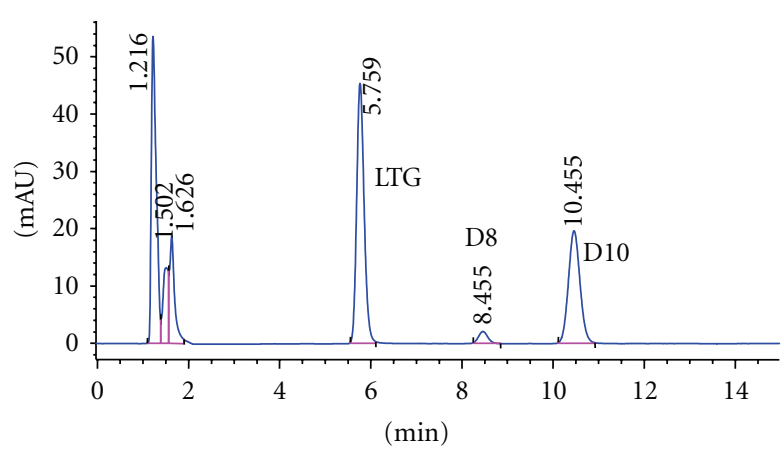

(b)

FIGURE 4: Chromatograms obtained with acid hydrolysis associated with temperature (a) and alkaline hydrolysis associated with temperature (b). The DP8 and DP10 are the degradation products formed.

LC method was optimized to resolve degradation products from the drug that were formed in acid and alkaline settings promoted by heat.

3.1.3. Linearity. Linearity was established by least squares linear regression analysis of the calibration curve. The regression equation for lamotrigine was found by plotting 
peak area $(y)$ versus the concentration $(x)$ studied from 10.0 to $80.0 \mu \mathrm{gmL}^{-1}$. The representative linear equation was $y=248167.3 x-11301.4$, and the correlation coefficient ( $r=0.9999)$ was highly significant. The validity of the assay was verified by analysis of variance (ANOVA), obtaining $\left(F_{\text {calculated }}=759224,7>F_{\text {critical }} ; P=.05\right)$ with no deviation from linearity $(P<.05)$.

3.1.4. Precision. The precision results of the HPLC method demonstrated that the variability was low with $\mathrm{CV}$ (\%) values ranging from 0.53 to 1.71 for intraday and 1.24 for interday precision. The CV values lower than $2 \%$ indicate the good precision of this method. At each level of the lamotrigine concentration, three determinations were performed.

3.1.5. Accuracy. At each level of lamotrigine concentration three determinations were performed. The mean recovery was (mean \pm SD) $99.67 \pm 1.30,98.20 \pm 1.63$ and $100.46 \pm 0.83$. These values show the good accuracy of the proposed HPLC method.

3.1.6. Robustness. The robustness testing was performed in order to evaluate the susceptibility of measurements due to deliberate variations in analytical conditions [19, 23]. The changes in operational parameters did not lead to important changes in the performance of chromatographic system. The response determined in the robustness test is the percentage of the drug in relation to the nominal dose on tablet sample, and the CV\% between them was 0.77. The robustness study has proved that in every employed condition, the chromatographic parameters agreed with established values and the assay data remained acceptable.

3.1.7. Sensitivity. The LOD value obtained with the signal-to-noise about 3.8:1 was in the concentration of $0.05 \mu \mathrm{gmL}^{-1}$ of the drug. The LOQ value obtained with the signal-to-noise about 10:1 was in the concentration of $0.15 \mu \mathrm{gmL}^{-1}$ of the drug. These results showed the good sensitivity of the method to determine and quantify lamotrigine.

3.1.8. System Suitability. System suitability was evaluated to verify if the chromatographic system was adequate for the analysis to be done. The approximate results were theoretical plates $(N=8430)$, capacity factor $(k=3.35)$, peak asymmetry, or tailing factor $(t=1.16)$. The values for these parameters were satisfactory in accordance with the literature $[28,29]$.

3.1.9. Solution Stability. The solution evaluated demonstrated to be stable at least for 30 days in methanol and for 15 days in $\mathrm{HCl} 0.01 \mathrm{M}$.

\subsection{UV Method}

3.2.1. Selection of UV Conditions. The UV-VIS method is extensively used in quality control of pharmaceutical products due to the potential of the great majority of

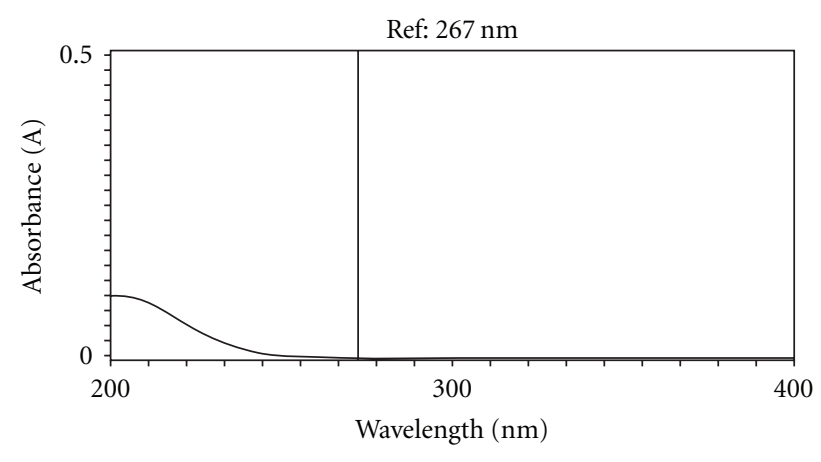

FIgURE 5: Specificity of the UV method.

the drugs to absorb energy in these wavelengths. Lamotrigine presents a structure with aromatic rings, making the absorption in UV region possible. The method is fast, easy, of low cost and shows the advantage of not generating a lot of solvent discharges [30]. At first, different solvents like methanol, ethanol, $0.1 \mathrm{M} \mathrm{HCl}$, and $0.01 \mathrm{M} \mathrm{HCl}$ were tested. The maximum absorption region in different solvents and their intensities could be determined by UV spectrophotometer. The lamotrigine solutions prepared with ethanol and methanol demonstrated maximum absorption in $307 \mathrm{~nm}$ and solutions prepared with $\mathrm{HCl}$ presented maximum absorption at $267 \mathrm{~nm}$. After preliminary tests, the choice was the use of $0.01 \mathrm{M} \mathrm{HCl}$. This solvent was evaluated for the development of the analytical method, in which the drug was shown stable during the studied period and presents the advantage of eliminating organic solvents in the analysis.

3.2.2. Specificity. The specificity determination is very important during the validation of nonchromatographic methods, since there is no step of separation before the determination $[30,31]$. In pharmaceutical analysis, UV spectrophotometer can be a quantitative method when there is no interference of the inactive ingredients of the pharmaceutical formulation. The UV spectra obtained through the analysis of the placebo solution did not present any interference in the maximum of $267 \mathrm{~nm}$ of lamotrigine, demonstrating the specificity of the method. The spectrum is showed in Figure 5.

3.2.3. Linearity. Linearity for UV method was determined over the concentrations ranging of 5.0 and $40.0 \mu \mathrm{gmL}^{-1}$, with significantly high value of correlation coefficient $(r=$ 0.9999 ) and the linear regression equation $y=0.0294 x+$ 0.0009 . The validity of the assay was verified by means of the ANOVA. According to it, there is linear regression and there is no deviation from linearity $(P<.05)$.

3.2.4. Precision. The precision experimental values obtained for UV method were for intraday ranging from 0.35 to 1.17 and 0.71 for interday precision. The results showed the low $\mathrm{CV}(\%)$ and the good precision of this method. 
TABle 1: Parameters used in UV method robustness test in the extraction of lamotrigine from the tablets.

\begin{tabular}{lcc}
\hline Extraction parameters & Mean (\%) & CV (\%) \\
\hline 15 min-mechanical shaker & 97,74 & 0,47 \\
15 min-ultrasonicator bath & 97,25 & 1,26 \\
$\begin{array}{l}\text { Both parameters (15 min + 15 min) of each } \\
\text { one }\end{array}$ & 97,61 & 0,39 \\
\hline
\end{tabular}

3.2.5. Accuracy. The analytical accuracy is the nearness of the results obtained against the real values [30]. At each level of lamotrigine concentration, three determinations were performed. The results were expressed as percent recoveries and the means were 97,6, 98,9, and 99,4\%. These values showed the good accuracy of the UV proposed method.

3.2.6. Robustness. The results of the experiments in the robustness test for UV method are expressed in percentage of the drug in relation to the nominal dose, calculated using a standard solution. The values obtained for different extraction procedures are demonstrated in Table 1. The validity of the assay was verified by means of the ANOVA. According to it, $F_{\text {calculated }}=0.66<F_{\text {theoretical }}=5.14$.

3.2.7. Sensitivity. The LOD and LOQ values mathematically obtained for UV method were $0.29 \mu \mathrm{gmL}^{-1}$ and $0.88 \mu \mathrm{gmL}^{-1}$, respectively.

\subsection{Comparison between LC and UV Methods for Lamotrigine} Determination. The comparison between the UV (98.42 \pm 0.71 ; mean $(\%) \pm S D)$ and the HPLC method (98.64 \pm 0.65 ; mean $(\%) \pm \mathrm{SD})$ was performed through the statistical $t$ student test at 0.05 significant level of the mean experimental values obtained in the determination of lamotrigine in tablets by each method. The test did not show statistical difference between the two techniques $\left(t_{\text {calculated }}=0.7338<\right.$ $t_{\text {theoretical }}=2.0322$ ).

The LC method developed is very simple, and results confirm suitable accuracy, specificity, and precision. In this study, a HPLC and an UV method were developed and validated for the quantitative determination of lamotrigine in tablets. There is no significant difference between the validated LC method and UV method, suggesting that both can be interchangeable.

\section{Acknowledgment}

The authors wish to thank LEPCQ, LCQFar for technical support.

\section{References}

[1] F. D. Fuchs and L. Wannmacher, Farmacologia Clínica, Guanabara Koogan, Rio de Janeiro, Brazil, 2004.

[2] J. O. McNamara, Goodman \& Gilmans: As Bases Farmacológicas da Terapêutica, McGraw Hill, Rio de Janeiro, Brazil, 2003.
[3] E. Ben-Menachem, "New antiepileptic drugs and nonpharmacological treatments," Current Opinion in Neurology, vol. 13, no. 2, pp. 165-170, 2000.

[4] C. L. Cheng, C. H. Chou, and O. Y. P. Hu, "Determination of lamotrigine in small volumes of plasma by highperformance liquid chromatography," Journal of Chromatography B, vol. 817, no. 2, pp. 199-206, 2005.

[5] D. Croci, A. Salmaggi, U. De Grazia, and G. Bernardi, "New high-performance liquid chromatographic method for plasma/serum analysis of lamotrigine," Therapeutic Drug Monitoring, vol. 23, no. 6, pp. 665-668, 2001.

[6] M. M. Castel-Branco, A. M. Almeida, A. C. Falcão, T. A. Macedo, M. M. Caramona, and F. G. Lopez, "Lamotrigine analysis in blood and brain by high-performance liquid chromatography," Journal of Chromatography B, vol. 755, no. 1-2, pp. 119-127, 2001.

[7] M. Torra, M. Rodamilans, S. Arroyo, and J. Corbella, "Optimized procedure for lamotrigine analysis in serum by highperformance liquid chromatography without interferences from other frequently coadministered anticonvulsants," Therapeutic Drug Monitoring, vol. 22, no. 5, pp. 621-625, 2000.

[8] N. R. Barbosa and A. F. Midio, "Validated high-performance liquid chromatographic method for the determination of lamotrigine in human plasma," Journal of Chromatography B, vol. 741, no. 2, pp. 289-293, 2000.

[9] Y. Bottiger, J. O. Svensson, and L. Stahle, "Lamotrigine drug interactions in a TDM material," Therapeutic Drug Monitoring, vol. 21, no. 2, pp. 171-174, 1999.

[10] E. Vidal, C. Pascual, and L. Pou, "Determination of lamotrigine in human serum by liquid chromatography," Journal of Chromatography B, vol. 736, no. 1-2, pp. 295-298, 1999.

[11] P. Angelis-Stoforidis, D. J. Morgan, T. J. O’Brien, and F. J. E. Vajda, "Determination of lamotrigine in human plasma by high-performance liquid chromatography," Journal of Chromatography B, vol. 727, no. 1-2, pp. 113-118, 1999.

[12] K. M. Matar, P. J. Nicholls, S. A. Bawazir, M. I. Al-Hassan, and A. Tekle, "A rapid liquid chromatographic method for the determination of lamotrigine in plasma," Journal of Pharmaceutical and Biomedical Analysis, vol. 17, no. 3, pp. 525-531, 1998.

[13] B. C. Sallustio and R. G. Morris, "High-performance liquid chromatography quantitation of plasma lamotrigine concentrations: application measuring trough concentrations in patients with epilepsy," Therapeutic Drug Monitoring, vol. 19, no. 6, pp. 688-693, 1997.

[14] M. Cociglio, R. Alric, and O. Bouvier, "Performance analysis of a reversed-phase liquid chromatographic assay of lamotrigine in plasma using solvent-demixing extraction," Journal of Chromatography, vol. 572, no. 1-2, pp. 269-276, 1991.

[15] S. M. Addolorata, B. Francesca, C. Matteo, A. Mario, and M. A. Raggi, "Rapid HPLC analysis of the antiepileptic lamotrigine and its metabolites in human plasma," Journal of Separation Science, vol. 30, no. 14, pp. 2249-2255, 2007.

[16] S. Bompadre, A. Tagliabracci, M. Battino, and R. Giorgetti, "Determination of lamotrigine in whole blood with on line solid phase extraction," Journal of Chromatography B, vol. 863, no. 1, pp. 177-180, 2008.

[17] E. Griner-Sosanko, D. R. Lower, M. A. Virji, and M. D. Krasowski, "Simultaneous determination of lamotrigine, zonisamide and carbamazepine in human plasma by highperformance liquid chromatography," Biomedical Chromatography, vol. 21, no. 3, pp. 225-228, 2007. 
[18] J. Emami, N. Ghassami, and F. Ahmadi, "Development and validation of a new HPLC method for determination of lamotrigine and related compounds in tablet formulations," Journal of Pharmaceutical and Biomedical Analysis, vol. 40, no. 4, pp. 999-1005, 2006.

[19] N. F. Youssef and E. A. Taha, "Development and validation of spectrophotometric, TLC and HPLC methods for the determination of lamotrigine in presence of its impurity," Chemical and Pharmaceutical Bulletin, vol. 55, no. 4, pp. 541545, 2007.

[20] S. Pollisetty, M. Khagga, R. R. Buchi, and S. S. V. Koduvi, "Development of a validated stability indicating LC method for lamotrigine," Chromatographia, vol. 70, no. 1-2, pp. 271276, 2009.

[21] International Conference on Harmonization (ICH), "Validation of Analytical Procedures: Validation of Analytical Procedures: methodology Q2B," Consensus Guideline, November 1996.

[22] British Pharmacopoeia 2005, Not Avail, London, UK, 2005.

[23] United States Pharmacopeia, USP Convention, Rockville, Md, USA, 2008.

[24] S. Klick, P. G. Muijselaar, J. Waterval et al., "Toward a generic approach for: Stress testing of drug substances and drug products," Pharmaceutical Technology, vol. 29, no. 2, pp. 4866, 2005.

[25] Proceedings of the International Conference on Harmonization (ICH), Stability Testing of New Drug Substance and Products: Methodology Q1A(R2), 2003.

[26] Proceedings of the International Conference on Harmonization (ICH), Harmonized Tripartite Guideline, Validation of Analytical Procedures: Text and Methodology Q2 (R1), 2005.

[27] M. Bakshi and S. Singh, "Development of validated stabilityindicating assay methods - critical review," Journal of Pharmaceutical and Biomedical Analysis, vol. 28, no. 6, pp. 1011-1040, 2002.

[28] R. L. Snyder, J. Kirkland, and L. Glajch, Pratical HPLC Method Development, Jonh Wiley \& Sons, Hoboken, NY, USA, 1997.

[29] G. A. Shabir, "Validation of high-performance liquid chromatography methods for pharmaceutical analysis: understanding the differences and similarities between validation requirements of the US Food and Drug Administration, the US Pharmacopeia and the International Conference on Harmonization," Journal of Chromatography A, vol. 987, no. 12, pp. 57-66, 2003.

[30] FDA, Center for Drug Evaluation and Research. Reviewer Guidance: Validation of Chromatographic Methods, Rockville, Md, USA, 1994.

[31] H. G. Brittain, "Validação de métodos não-cromatográficos," Pharmaceutical Technology, vol. 2, no. 3, p. 4, 1998. 


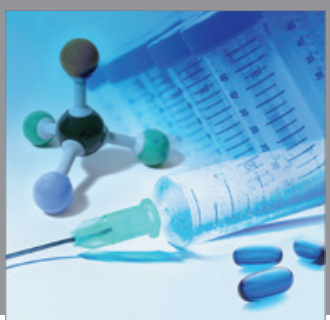

International Journal of

Medicinal Chemistry

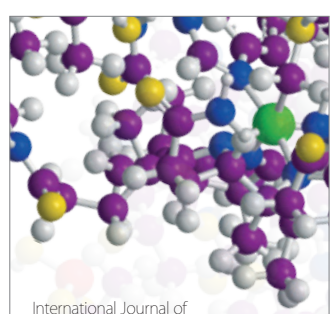

Carbohydrate Chemistry

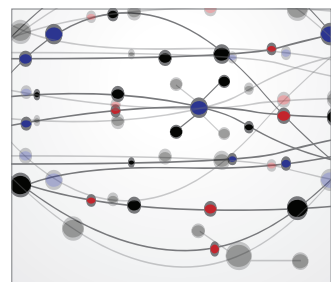

The Scientific World Journal
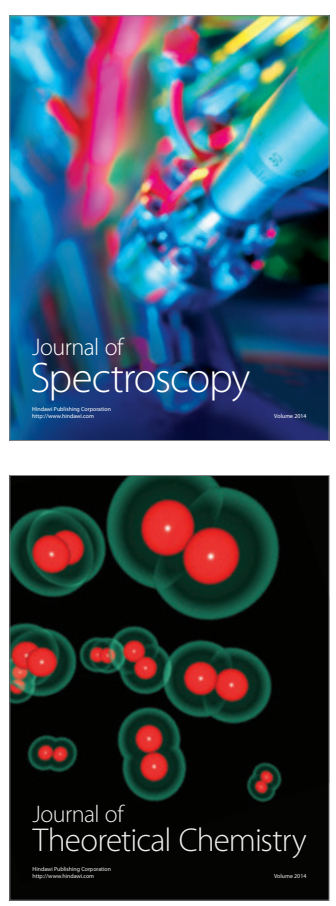
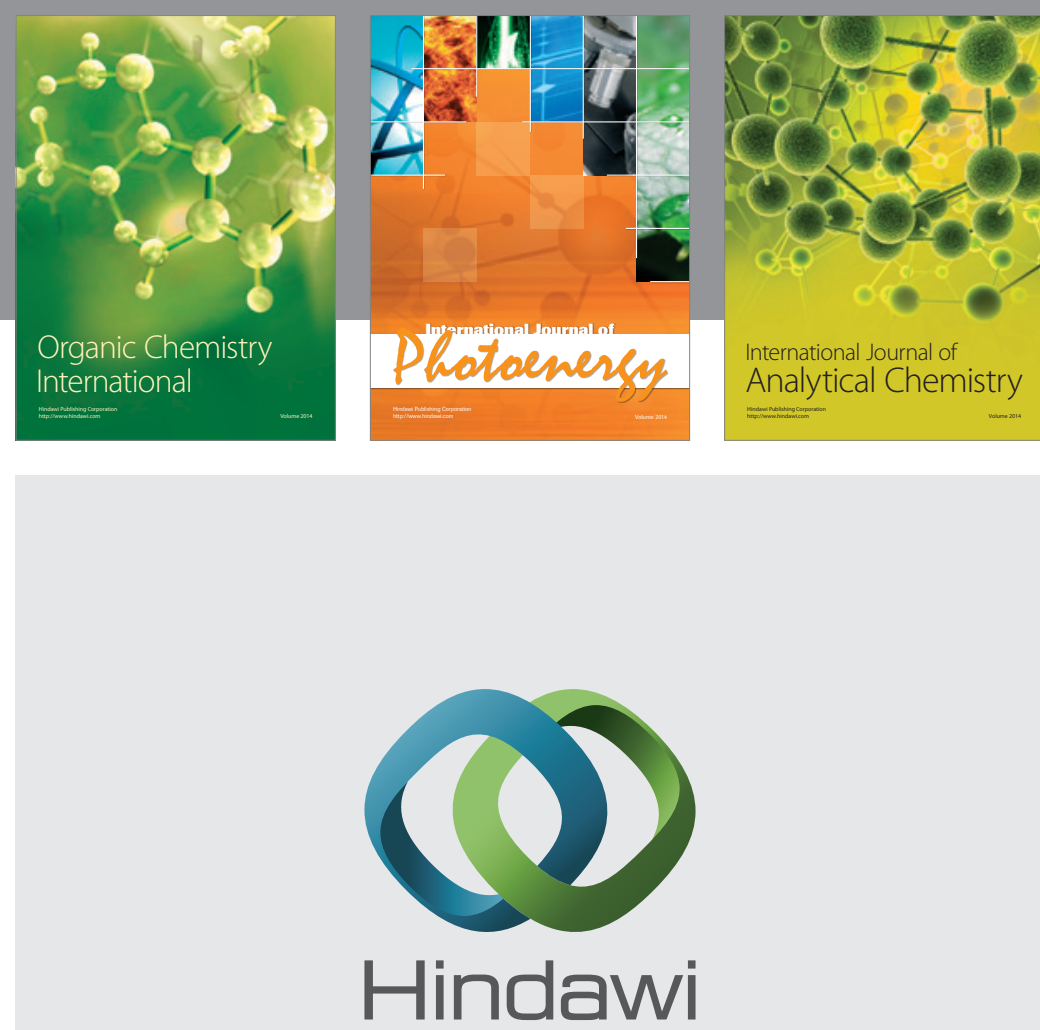

Submit your manuscripts at

http://www.hindawi.com
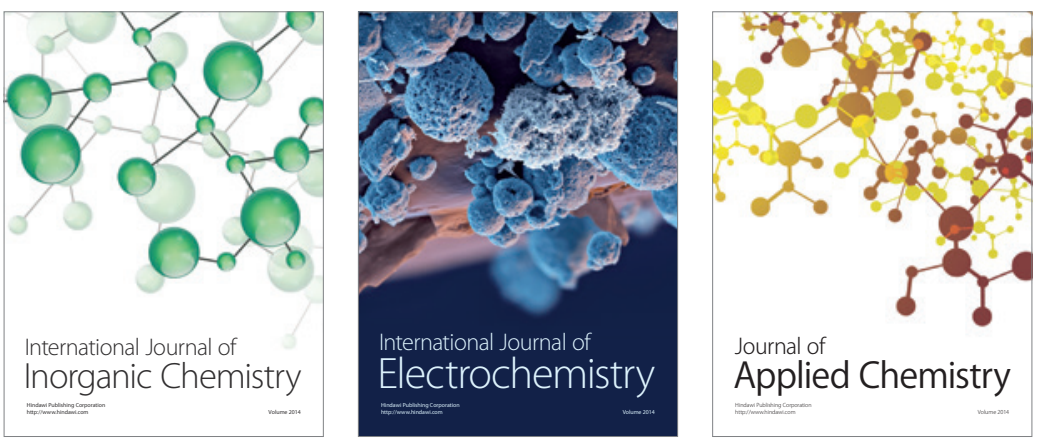

Journal of

Applied Chemistry
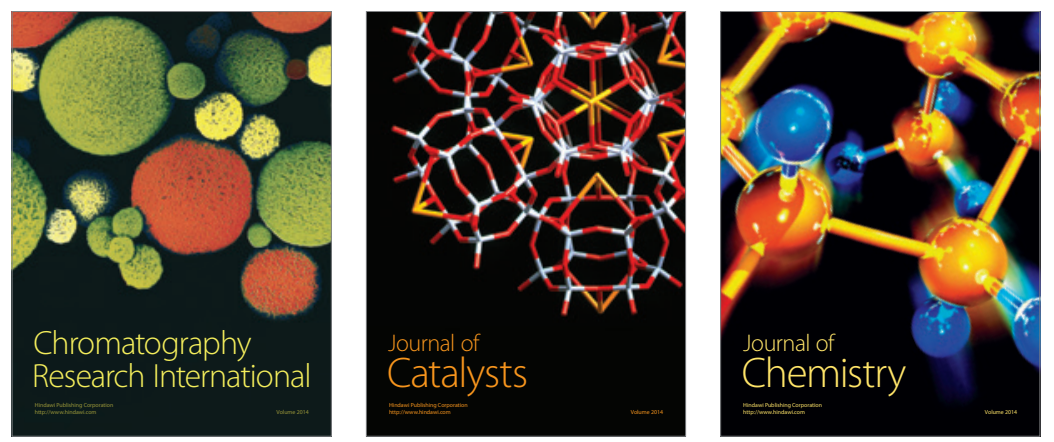
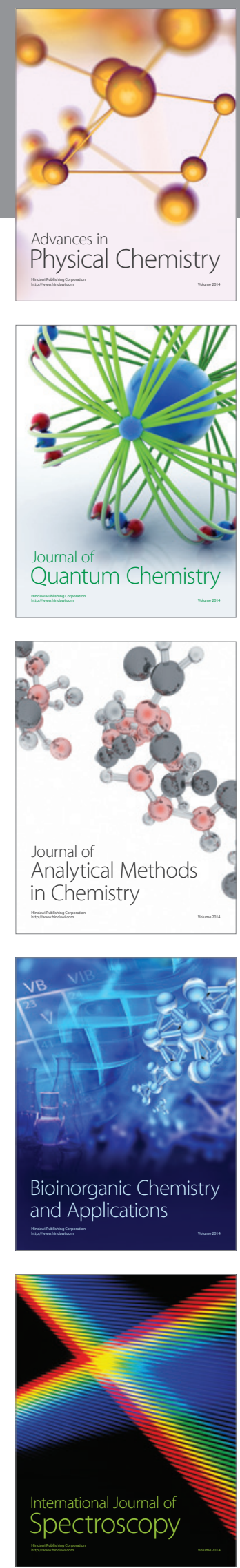